\title{
VCAM-1, but Not ICAM-1 or MAdCAM-1, Immunoblockade Ameliorates DSS-Induced Colitis in Mice
}

\author{
Antonio Soriano, Antonio Salas, Azucena Salas, Miquel Sans, Meritxell Gironella, \\ Monserrat Elena, Donald C. Anderson, Josep M. Piqué, and Julián Panés
}

Department of Gastroenterology (ASo, AzS, MS, MG, JMP, JP), Institut de Malalties Digestives, and Department of Biochemistry (ME), Hospital Clínic, Institut d'Investigacions Biomèdiques August Pi i Sunyer (IDIBAPS), University of Barcelona, and Department of Pathology (ASa), Hospital Mutua of Terrassa, Barcelona, Spain; and Discovery Research (DCA), Pharmacia and Upjohn Laboratories, Kalamazoo, Michigan

\begin{abstract}
SUMMARY: Adhesion molecule immunoneutralization is envisioned as a promising therapy for inflammatory bowel disease, but the relative value of selective blockade of different adhesion molecules has not been established. The aims of this study were to measure expression and functional relevance of endothelial intercellular adhesion molecule 1 (ICAM-1), vascular cell adhesion molecule 1 (VCAM-1), and mucosal addressin cell adhesion molecule 1 (MAdCAM-1) in leukocyte recruitment in experimental colitis and to compare the therapeutic effectiveness of their selective blockade. For this purpose, cell adhesion molecule expression was measured by the dual radiolabeled antibody technique in mice with dextran sulfate sodium-induced colitis and controls. Leukocyte-endothelial cell interactions were determined in colonic venules by fluorescence intravital microscopy. Therapeutic effects of chronic treatment with anti-ICAM-1, anti-VCAM-1, or anti-MAdCAM-1 antibodies were also assessed. Whereas colonic endothelial ICAM-1 was constitutively expressed and had a mild up-regulation in colitic animals, constitutive expression of VCAM-1 and MAdCAM-1 was low, but markedly increased after induction of colitis. Leukocyte adhesion was abrogated by immunoneutralization of VCAM-1 or MAdCAM-1 but not by treatment with an anti-ICAM-1 antibody. Chronic administration of anti-VCAM-1 antibody, but not anti-ICAM-1 or anti-MAdCAM-1, resulted in significant attenuation of colitis in terms of disease activity index, colon length, ratio of colon weight to length, and myeloperoxidase activity. In conclusion, VCAM-1 plays a central role in leukocyte recruitment in colitis and blockade of this adhesion molecule has higher therapeutic effect than immunoneutralization of ICAM-1 or MAdCAM-1 in this experimental model. (Lab Invest 2000, 80:1541-1551).
\end{abstract}

$T$ he immune responses that mediate local inflammation in inflammatory bowel disease (IBD) are not fully characterized. Nevertheless, there is little doubt that many cardinal signs of this inflammation are due to the rapid and prolonged infiltration of leukocytes together with the release of inflammatory mediators such as proteases, cytokines, arachidonic acid metabolites, and reactive oxygen species. These inflammatory mediators can damage cells either directly or indirectly through a mechanism secondary to increased leukocyte adhesion and infiltration (Kubes, 1993). Thus, central to the pathology of IBD is the role of molecules that regulate the recruitment of leuko-

Received July 7, 2000.

This work was supported by grant SAF00-0057 from Comision Interministerial de Ciencia y Tecnologia. Dr. A. Soriano is a recipient of a grant from Comissionat per a Universitats i Recerca de la Generalitat de Catalunya and from Sociedad Andaluza de Patología Digestiva. Dr. M. Sans is a recipient of a grant from SmithKline Beecham-Grupo Español de Trabajo en Enfermedad de Crohn y Colitis Ulcerosa.

Address reprint requests to: Dr. Julián Panés, Gastroenterology Department, Hospital Clinic, Villarroel 17008036 Barcelona, Spain. Fax: 3493 45168 77; E-mail:panes@medicina.ub.es cytes such as cell adhesion molecules (CAMs) (Springer, 1990).

Both leukocyte and endothelial CAMs participate in transmigration of leukocytes from the vascular compartment to tissue sites of inflammation or immune reactions. This process results from a complex series of events involving rolling, activation, firm adhesion, and subsequent migration of leukocytes across the vascular endothelium.

Intercellular adhesion molecule 1 (ICAM-1), vascular cell adhesion molecule 1 (VCAM-1), and mucosal addressin cell adhesion molecule 1 (MAdCAM-1) are endothelial CAMs of the immunoglobulin superfamily with a critical role in mediating the firm adhesion of leukocytes to endothelial cells in a variety of acute and chronic inflammatory diseases (Henninger et al, 1997; Panés and Granger, 1998). Immunohistochemistry studies of intestinal tissue samples from patients with IBD have demonstrated an increased expression of various CAMs, but there is no uniform agreement on their pattern of activation (Koizumi et al, 1992; Oshitani et al, 1995). The contradictory results of these studies may be in part related to limitations in quantification of CAM expression by this technique. Moreover, the functional significance of changes in expression of 
these CAMs in colonic venules on leukocyteendothelial cell interactions has only been directly assessed in a recent study in a model of trinitrobenzene sulfonic acid (TNBS)-induced colitis (Sans et al, 1999). Since immunoneutralization of CAMs is regarded as a new strategy for treatment of IBD, it is crucial to elucidate the functional relevance and potential therapeutic benefit of selective immunoneutralization of the different CAMs involved in the process of leukocyte recruitment in IBD.

In the present investigation we have used a wellstandardized model of mouse experimental colitis induced by oral administration of dextran sulfate sodium (DSS), characterized by morphological changes that mimic human ulcerative colitis (Okayasu et al, 1990). Using the dual radiolabeled monoclonal antibody (MAb) technique, an accurate method to quantify expression of CAMs in vivo (Eppihimer et al, 1996; Keelan et al, 1994; Langley et al, 1999; Panés et al, 1995), we have evaluated the pattern of CAM expression in DSS-induced colitis. To assess the functional significance of changes in CAM expression we have used intravital videomicroscopy, studying leukocyteendothelial cell interactions and its molecular determinants by means of selective acute immunoneutralization. Finally, we have investigated the effects of chronic treatment with anti-ICAM-1, anti-VCAM-1, and anti-MAdCAM-1 MAbs on tissue injury and clinical signs of IBD.

\section{Results}

\section{Study 1: Characterization of Inflammatory Changes}

Clinical, macroscopic, histological, and biochemical changes in control and colitic mice are summarized in Table 1. Administration of DSS induced a significant loss in body weight that was maximum at Days 7 and 8 after induction of colitis. Starting 24 hours after induction of colitis, all animals had a positive fecal occult blood test and diminished stool consistency when compared with control animals. A Disease Activity Index (DAl) combining these parameters, as detailed in Table 2, was increased in DSS-treated mice. Colitic mice also had a significant reduction in colon length and an increase in colon weight, as well as an increase in the ratio of colon weight to length. Histological damage was seen only in colitic animals. Myeloperoxidase (MPO) activity in colonic samples were 4-fold higher in colitic animals than in control mice.
Table 2. Criteria for Scoring Disease Activity Index ${ }^{1}$ (reproduced from Murphy et al, 1993)

\begin{tabular}{crll}
\hline Score & $\begin{array}{c}\text { Weight loss } \\
(\%)\end{array}$ & $\begin{array}{c}\text { Stool } \\
\text { consistency }\end{array}$ & Rectal bleeding \\
\hline 0 & None & Normal & Negative \\
1 & $1-5$ & Loose & Negative \\
2 & $5-10$ & Loose & Hemoccult positive \\
3 & $10-15$ & Diarrhea & Hemoccult positive \\
4 & $>15$ & Diarrhea & Gross bleeding \\
\hline
\end{tabular}

${ }^{1}$ Disease activity index $=$ combined score of weight loss, stool consistency, and bleeding $/ 3$.

${ }^{2}$ Normal stools $=$ well-formed pellets; loose stools = pasty stool that does not stick to the anus; and diarrhea = liquid stool that sticks to the anus.

\section{Study 2: In Vivo Expression of ICAM-1, VCAM-1, and MAdCAM-1}

Values for colon endothelial surface area per gram of tissue, estimated from endothelial binding of antiintercellular adhesion molecule 2 (ICAM-2) MAb 3C4, were $350.0 \pm 92.0 \mathrm{ng} \mathrm{MAb/g}$ tissue in colitic animals and $277.2 \pm 27.8 \mathrm{ng} \mathrm{MAb/g}$ tissue in controls; this difference was not significant $(p=0.47)$. Binding of the anti-ICAM-2 MAb was also similar in control and colitic mice in other organs, including liver, pancreas, mesentery, stomach, small intestine, and cecum (Table 3). Therefore, values for endothelial anti-ICAM-1, anti-VCAM-1, and anti-MAdCAM-1 binding were not corrected for changes in endothelial surface area relative to organ weight that might result from edema or capillary recruitment.

Endothelial ICAM-1 expression in the colon of colitic mice, estimated as bound $\mathrm{ng} \mathrm{MAb} / \mathrm{g}$ tissue, was significantly increased compared with noncolitic mice, although this increase was relatively mild (Fig. 1). In contrast, colonic endothelial VCAM-1 and MAdCAM-1 expression showed a marked increase (3-fold over control values) 10 days after induction of colitis (Fig. 1). ICAM-1 expression in organs other than the colon and the stomach remained unmodified in colitic animals (Table 3). However, VCAM-1 expression was also significantly increased in mesentery, ileum, and cecum and MAdCAM-1 expression was up-regulated in mesentery, stomach, and cecum (Table 3). No accumulation of the anti-MAdCAM-1 antibody was observed in liver, spleen (Table 3), or other extraabdominal organs such as heart or lung (data not shown), which is consistent with a restricted expres-

Table 1. Clinical, Macroscopic, Histological, and Biochemical Changes in Control and DSS-Treated Mice

\begin{tabular}{|c|c|c|c|c|c|c|c|c|c|}
\hline Group & $\begin{array}{c}\Delta \text { Body } \\
\text { weight }(\mathrm{g})\end{array}$ & $\begin{array}{c}\text { Stool } \\
\text { consistency }\end{array}$ & $\begin{array}{l}\text { Rectal } \\
\text { bleeding }\end{array}$ & DAI & $\begin{array}{l}\text { Colon weight } \\
\text { (mg) }\end{array}$ & $\begin{array}{l}\text { Colon length } \\
\qquad(\mathrm{mm})\end{array}$ & $\begin{array}{c}\text { Colon } \\
\text { weight/ } \\
\text { length } \\
\text { (mg/mm) }\end{array}$ & $\begin{array}{c}\text { Microscopic } \\
\text { score }\end{array}$ & $\begin{array}{c}\text { MPO } \\
\text { activity } \\
\text { (U/g tissue) }\end{array}$ \\
\hline Control & $0.2 \pm 0.2$ & $0 \pm 0$ & $0 \pm 0$ & $0 \pm 0$ & $297.3 \pm 7.7$ & $95.6 \pm 1.4$ & $3.1 \pm 0$ & $0 \pm 0$ & $0.4 \pm 0.07$ \\
\hline DSS & $-2.2 \pm 0.3^{a}$ & $1.0 \pm 0.1^{b}$ & $1.3 \pm 0^{b}$ & $1.7 \pm 0.1^{b}$ & $340 \pm 11.8^{a}$ & $73.7 \pm 1.7^{b}$ & $4.6 \pm 0.1^{b}$ & $52.1 \pm 6.7^{b}$ & $1.9 \pm 0.3^{a}$ \\
\hline
\end{tabular}


Table 3. Endothelial CAMs Expression in ng MAb per Gram of Tissue $(\mathrm{ng} / \mathrm{g})$ in Different Vascular Beds in Control and DSS-Treated Mice

\begin{tabular}{lcccccccc}
\hline \multicolumn{1}{c}{ Liver } & Spleen & Pancreas & Mesentery & Stomach & Jejunum & lleum & Cecum \\
\hline ICAM-1 & & & & & & & & \\
$\quad$ Control & $7679 \pm 662.9$ & $7614 \pm 777.9$ & $372 \pm 20.7$ & $440.8 \pm 38.9$ & $305 \pm 22.3$ & $436.3 \pm 46.1$ & $356.5 \pm 29.1$ & $300.5 \pm 23.3$ \\
DSS & $8469 \pm 440.7$ & $6721 \pm 531.3$ & $493.7 \pm 100.9$ & $523.7 \pm 95.2$ & $438 \pm 43^{a}$ & $437.8 \pm 51.5$ & $350.8 \pm 27.9$ & $306.2 \pm 27.4$ \\
ICAM-2 & & & & & & & & \\
Control & $846.2 \pm 239.8$ & $747.7 \pm 249.7$ & $320.7 \pm 48.8$ & $311.7 \pm 20$ & $485.5 \pm 40.6$ & $468.2 \pm 52.8$ & $410.2 \pm 54.6$ & $281.5 \pm 32.8$ \\
DSS & $722.2 \pm 143.2$ & $0 \pm 0^{a}$ & $443.7 \pm 28.3$ & $385.2 \pm 68.1$ & $493.5 \pm 31.5$ & $497.7 \pm 45.6$ & $421.2 \pm 43.5$ & $551 \pm 188$ \\
VCAM-1 & & & & & & & & \\
Control & $976.7 \pm 104$ & $7336.7 \pm 666.8$ & $56.7 \pm 6.8$ & $81.7 \pm 3.4$ & $64.7 \pm 7.6$ & $91 \pm 21.9$ & $41.7 \pm 4.3$ & $31 \pm 1.6$ \\
DSS & $1149.8 \pm 188.3$ & $5782.5 \pm 601.2$ & $79.4 \pm 13.1$ & $168 \pm 32.1^{a}$ & $77.6 \pm 7.2$ & $110.2 \pm 11.7$ & $59.6 \pm 5.3^{a}$ & $59.2 \pm 6.6^{a}$ \\
MAdCAM-1 & & & & & & & & \\
Control & $0 \pm 0$ & $0 \pm 0$ & $19.6 \pm 15.3$ & $58.3 \pm 16.7$ & $13.6 \pm 10.3$ & $268.6 \pm 32.5$ & $302.3 \pm 49.8$ & $85 \pm 24.8$ \\
DSS & $0 \pm 0$ & $0 \pm 0$ & $28.4 \pm 3.8$ & $158.4 \pm 30.3^{a}$ & $40 \pm 4.9^{a}$ & $253.2 \pm 7.6$ & $325.8 \pm 16.1$ & $220.2 \pm 36.4^{a}$ \\
\hline
\end{tabular}

${ }^{a} p<0.05$ vs control.

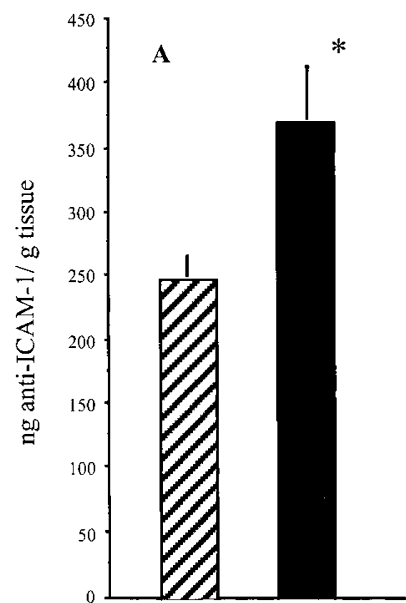

control colitis

ICAM-1

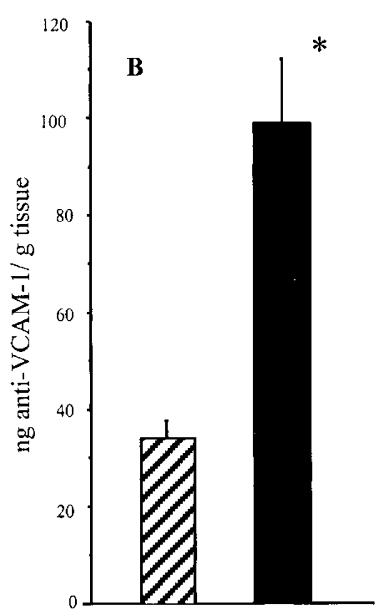

control colitis

VCAM-1

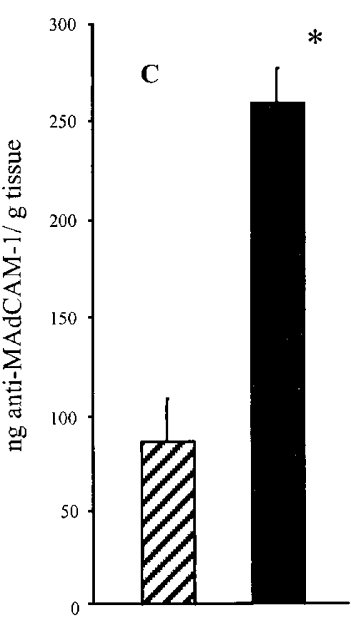

control colitis

MAdCAM-1

Figure 1.

$A$, Expression of colonic ICAM-1; B, VCAM-1; and C, MAdCAM-1 in control mice (hatched) and colitic animals (solid). ICAM-1 expression was estimated by binding of the anti-ICAM-1 MAb YN1/1.7.4, VCAM-1 expression by binding of the anti-VCAM-1 MAb MK1.91, and MAdCAM-1 expression by binding of anti-MAdCAM-1 MAb MECA-367. Note the different scales. Results are calculated as ng MAbs/g tissue. ${ }^{*} p<0.05$ vs control.

sion of this adhesion molecule to gastrointestinal organs.

\section{Study 3: Leukocyte-Endothelial Cell Interactions in Colonic Venules}

When compared with control animals, colitic mice showed a pronounced increase in leukocyte-endothelial cell interactions. There was a 3-fold increase in the flux of rolling leukocytes 10 days after induction of colitis (Fig. 2). Although few adherent leukocytes were present in venules from control mice, a 4-fold increase in leukocyte adhesion was observed in colitic animals (Fig. 2). No differences in leukocyte rolling velocity, venular blood flow, or venular wall shear rate were observed between control and colitic mice (not shown).

Treatment of colitic mice with anti-ICAM-1 MAb did not modify leukocyte adhesion to colonic venules, whereas VCAM-1 and MAdCAM-1 blockade decreased the number of adherent leukocytes to levels close to those of control animals (Fig. 3). Treatment of colitic mice with a nonbinding MAb (UPC-10) did not affect leukocyte adhesion to colonic venules. None of these MAbs had any effect on the flux of rolling leukocytes (Fig. 3), leukocyte rolling velocity, venular blood flow, or venular shear rate (not shown).

In view of the apparent discrepancy between the similar ability of anti-VCAM- 1 and anti-MAdCAM- 1 antibodies to prevent leukocyte adhesion in colitic animals studied at Day 10 after induction of colitis and the lack of therapeutic effect of anti-MAdCAM-1 antibodies (see below), we hypothesized that these two antibodies may have differential effects on leukocyte-endothelial cell interactions at an earlier time point. To test this hypothesis, we performed additional intravital microscopy studies in groups of colitic animals receiving the same antibodies, at Day 5 after induction of colitis. Comparison of colitic animals studied at Days 5 or 10 after induction of colitis revealed that the former group had a 

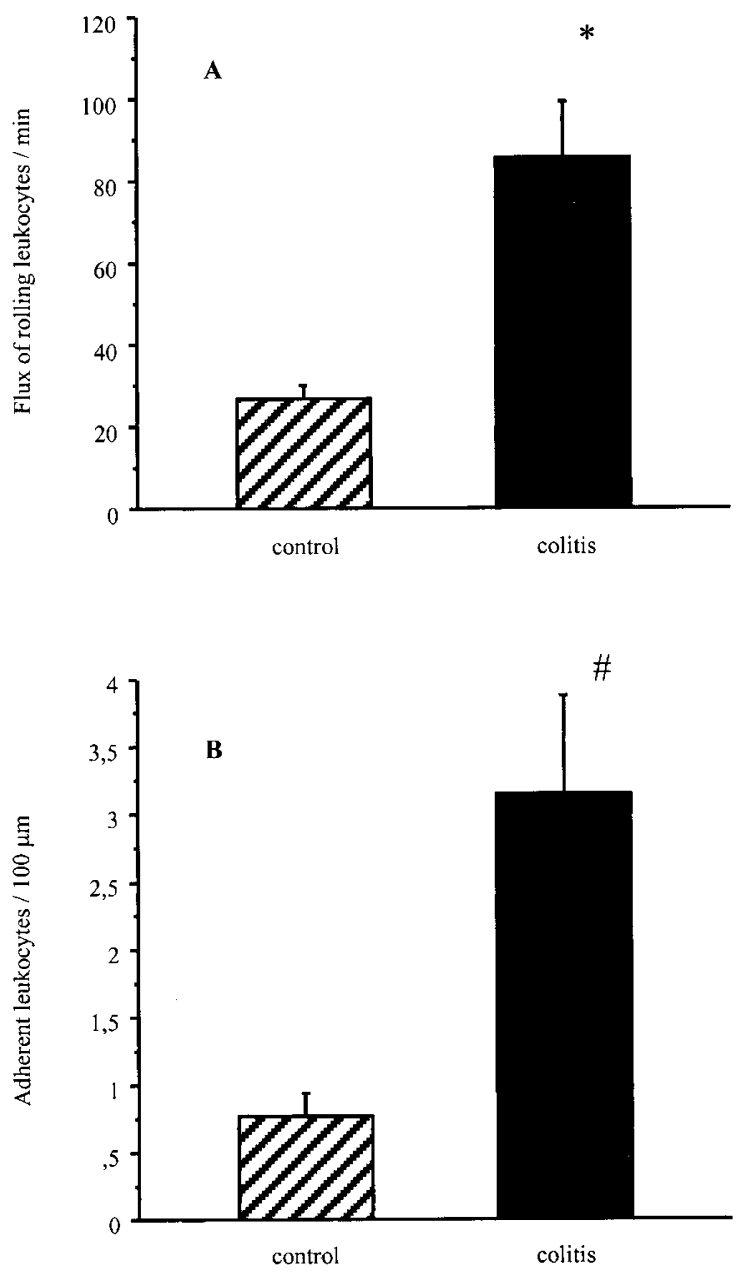

Figure 2.

$A$, Flux of rolling leukocytes and $B$, leukocyte adhesion in colonic venules. Control animals had a very low number of rolling or adherent leukocytes. A significant increment in leukocyte-endothelial cell interactions was observed at Day 10 after induction of colitis. ${ }^{*} p<0.01$ vs control; ${ }^{*} p<0.001$ vs control.

significantly lower flux of rolling leukocytes $(59.0 \pm 9.4$ vs. $85.3 \pm 14.0$ leukocytes/minute; $p<0.05)$, a higher number of adherent leukocytes $(5.8 \pm 0.4$ vs. $3.1 \pm 0.7$ cells $/ 100 \mu \mathrm{m}$ venule; $p<0.05)$, and a higher venular shear rate $\left(330.7 \pm 18.6\right.$ vs. $175.6 \pm 17.5$ seconds $^{-1} ; p<$ 0.05). The increased flux of rolling leukocytes observed in colitic mice at Day 5 after induction of colitis relative to control mice was abrogated by treatment with antiVCAM-1 MAb, but not by immunoneutralization of ICAM-1 or MAdCAM-1 (Table 4). Although treatment with anti-VCAM-1 and anti-MAdCAM-1 MAbs reduced leukocyte adhesion in colitic animals at Day 5, this reduction only reached statistical significance for the group treated with anti-VCAM-1 (Table 4).

Study 4: Effects of Chronic Treatment with Anti-ICAM-1, Anti-VCAM-1, and Anti-MAdCAM-1 MAb on DSS-Induced Colitis

Daily treatment with anti-VCAM-1 MAb MK1.91 significantly attenuated the loss in body weight as compared

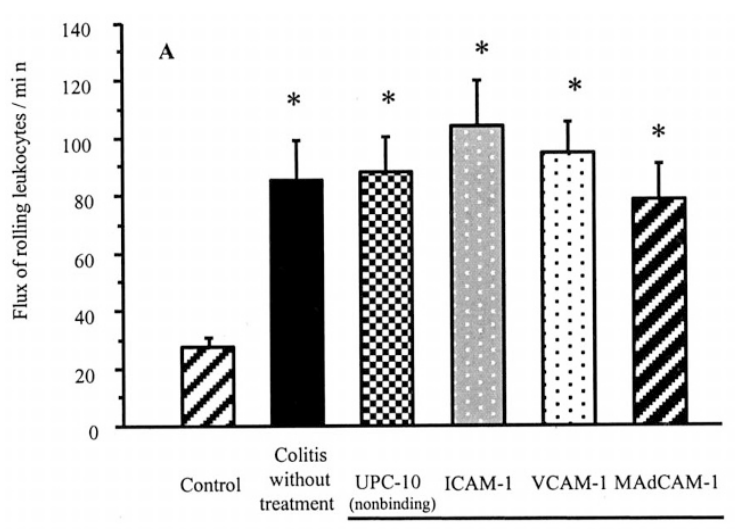

DSS-induced colitis $+\mathrm{mAb}$ anti-

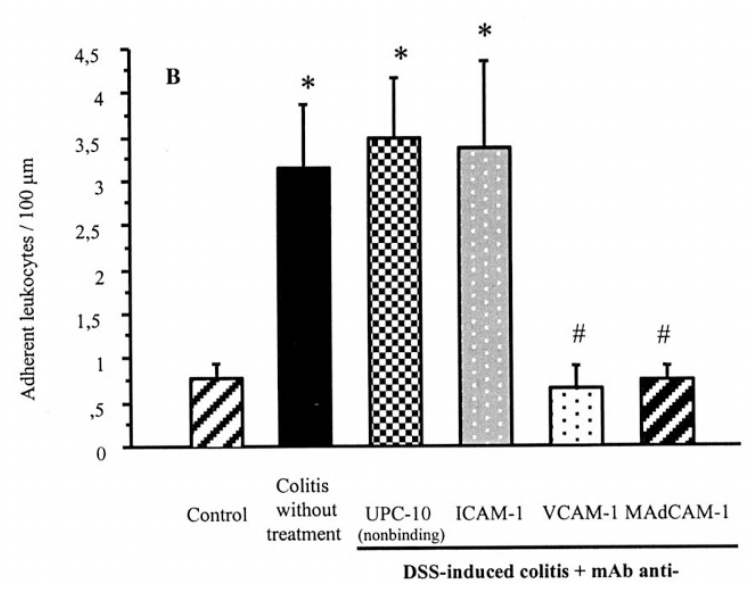

Figure 3.

Effects of immunoneutralization of ICAM-1, VCAM-1, and MAdCAM-1 on A, flux of rolling leukocytes and $B$, leukocyte adhesion. Immunoneutralization of either ICAM-1, VCAM-1, or MAdCAM-1 had no effect on leukocyte rolling. Blocking of VCAM-1 or MAdCAM-1 abrogated leukocyte adhesion in colonic venules of colitic mice, whereas ICAM-1 blockade did not have any effect. Control MAb UPC-10 had no effect. ${ }^{*} p<0.02$ vs control; ${ }^{\#} p<0.02$ vs colitis without treatment.

with the group of animals treated with the nonbinding MAb UPC-10, from Day 7 to Day 10 after induction of colitis (Fig. 4). In addition, animals treated with MK1.91 rapidly regained weight, whereas in those receiving the control MAb the decrease in body weight persisted as far as Day 9. DAl at Day 10 was significantly lower in mice treated with anti-VCAM-1 MAb than in the control group (Fig. 4). Compared with mice treated with the control MAb, MK1.91-treated animals had a significantly reduced colon weight $(252.4 \pm 14.6$ vs. $302.4 \pm 9.6 \mathrm{mg}$; $p<0.05$ ), lower reduction in colon length (Fig. 5), lower ratio of colon weight to length (Fig. 5), and lower colonic MPO activity (Fig. 6). Although the global microscopic damage score tended to be lower in MK 1.91-treated animals compared with those receiving the nonbinding MAb UPC-10 ( $34.8 \pm 14.9$ vs. $69.2 \pm 23.1)$, these results did not reach statistical significance. Neither administration of anti-ICAM-1 nor anti-MAdCAM-1 MAbs had significant effects on body weight loss, DAl, macroscopic, histological, or biochemical alterations associated with DSS-induced colitis as shown in Figures 4 to 6 . Differences in the severity of colitis among treatment 
Table 4. Leukocyte-Endothelial Cell Interactions at Day $\mathbf{5}$ after Colitis Induction

\begin{tabular}{|c|c|c|c|c|c|c|}
\hline \multirow[b]{2}{*}{ Group } & \multirow[b]{2}{*}{ Control } & \multirow[b]{2}{*}{$\begin{array}{l}\text { Colitis without } \\
\text { treatment }\end{array}$} & \multicolumn{4}{|c|}{ DSS-induced colitis + MAb anti- } \\
\hline & & & $\begin{array}{c}\text { UPC-10 } \\
\text { (nonbinding) }\end{array}$ & ICAM-1 & VCAM-1 & MAdCAM-1 \\
\hline $\begin{array}{l}\text { Flux of rolling leukocytes/min } \\
\text { Adherent leukocytes/100 } \mu \mathrm{m}\end{array}$ & $\begin{aligned} 27.1 & \pm 3.1 \\
0.8 & \pm 0.1\end{aligned}$ & $\begin{aligned} 59.0 & \pm 9.4^{a} \\
5.8 & \pm 0.4^{a}\end{aligned}$ & $\begin{aligned} 55.4 & \pm 11.7^{a} \\
5.5 & \pm 1.1^{a}\end{aligned}$ & $\begin{aligned} 61.2 & \pm 14.1^{a} \\
4.6 & \pm 2.2^{a}\end{aligned}$ & $\begin{aligned} 30.8 & \pm 5.9^{b} \\
3.1 & \pm 0.6^{a, b}\end{aligned}$ & $\begin{aligned} 51.6 & \pm 4.2^{a} \\
3.6 & \pm 0.6^{a}\end{aligned}$ \\
\hline
\end{tabular}

${ }^{a} p<0.05$ vs control.

${ }^{b} p<0.05$ vs colitis without treatment.
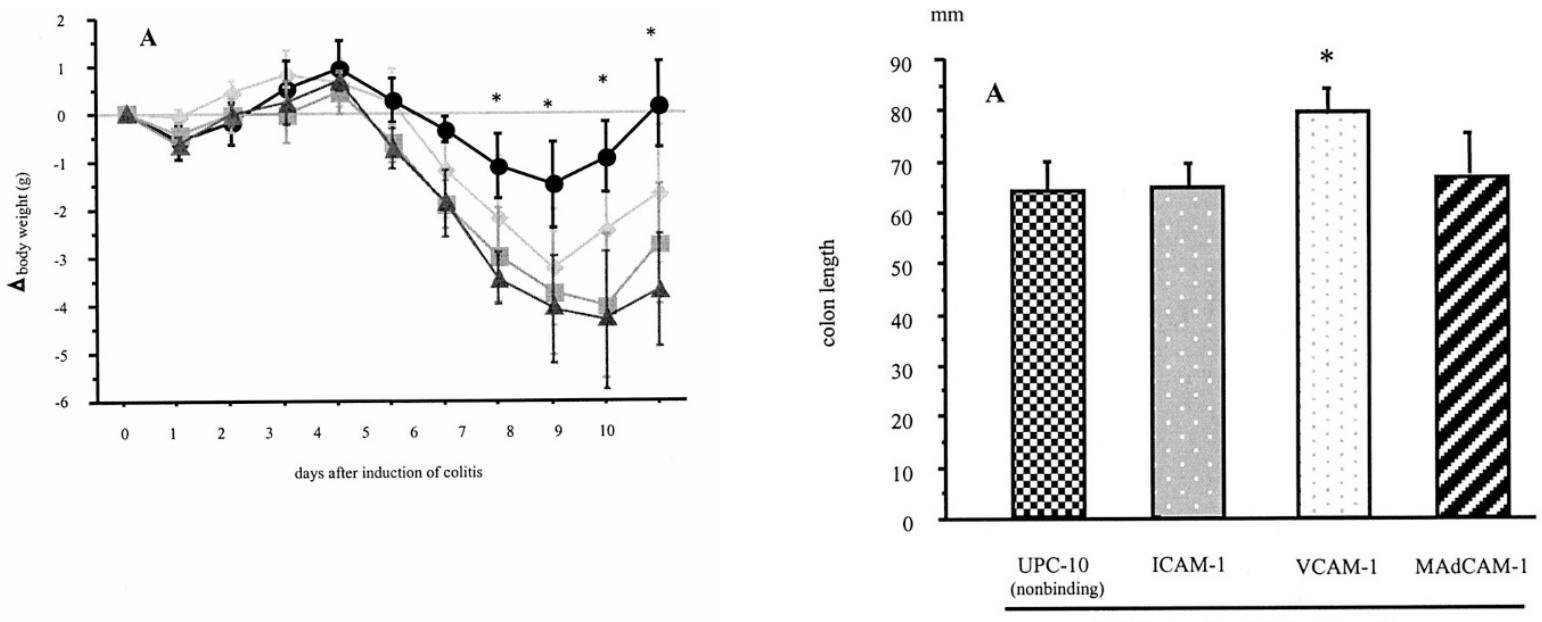

DSS-induced colitis + mAb anti-
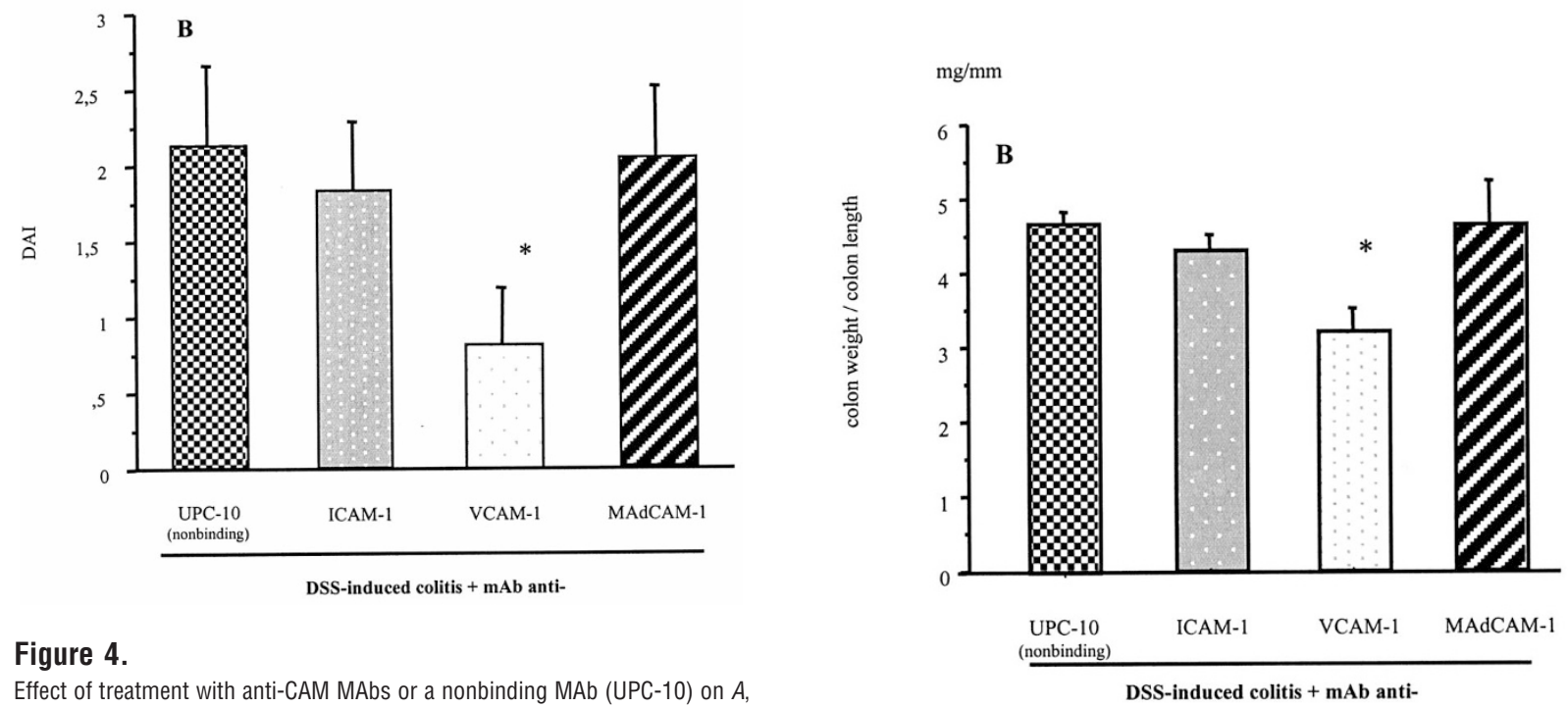

Figure 4.

Effect of treatment with anti-CAM MAbs or a nonbinding MAb (UPC-10) on A, body weight loss and $B$, DAI. Treatment with MK1.91 significantly attenuated the loss in body weight from Days 7 to 10 after induction of colitis, induced a more rapid recovery, and resulted in a lower DAI. $\$$, YN1/1.7.4 (anti-ICAM-1

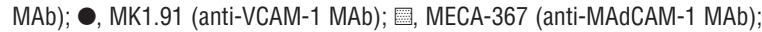
$\triangle$, UPC-10 (control MAb). ${ }^{\star} p<0.05$ vs UPC-10 treated colitic mice.

groups cannot be attributed to variations in exposure to DSS because the volume of drinking water with DSS consumed by the different groups was similar (not shown).

\section{Discussion}

In the present study we assessed the expression and functional role of three inducible endothelial CAMs,

\section{Figure 5.}

$A$, Colon length and $B$, ratio of colon weight to length after treatment with the different anti-CAM MAbs. Treatment of DSS-induced colitis with MK1.91 resulted in a marked reduction of macroscopic damage. ${ }^{*} p<0.05$ vs UPC-10 treated colitic mice.

namely ICAM-1, VCAM-1, and MAdCAM-1, in a wellcharacterized model of murine colitis. Likewise, we compared the therapeutic effectiveness of selective blockade of these molecules. Our results demonstrate a marked increase of endothelial VCAM-1 and MAdCAM-1 in the colon of colitic mice, a key functional role for these molecules as mediators of leuko- 


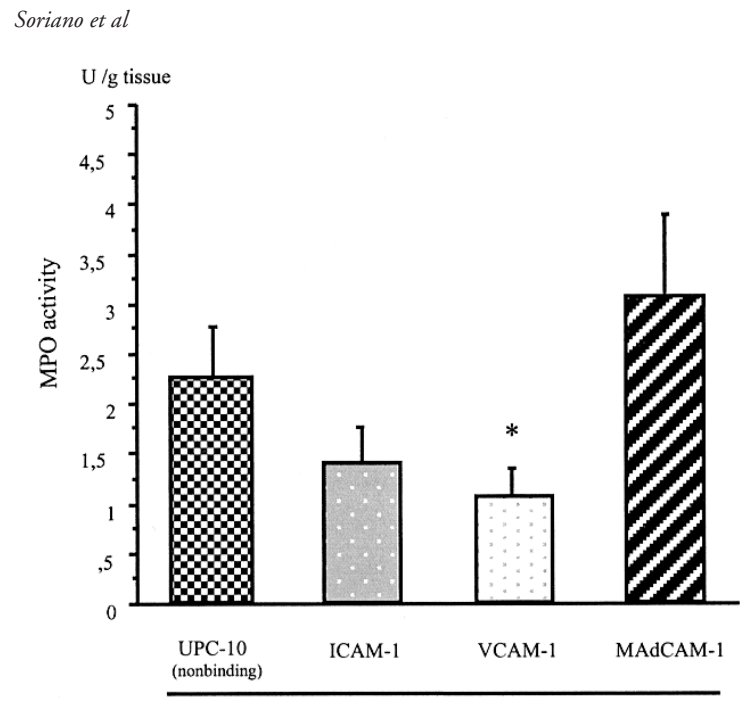

DSS-induced colitis + mAb anti-

Figure 6 .

Effect of treatment with anti-CAM MAbs or UPC-10 MAb on MPO activity. ${ }^{*} p$ $<0.05$ vs UPC- 10 treated colitic mice.

cyte adhesion, and a potent therapeutic effect for VCAM-1 immunoneutralization in DSS-induced colitis.

The dual-radiolabeled MAb technique has previously been employed to assess expression of different CAMs in vivo, in normal and inflamed tissues. Using this technique we demonstrated that expression of CAMs of the immunoglobulin superfamily is up-regulated in DSSinduced colitis, although the magnitude of the increase varies and is related to the level of basal expression. Hence, whereas ICAM-1 has a high constitutive expression and a weak, although significant, up-regulation in colitic animals, VCAM-1 and MAdCAM-1, which have a considerably lower basal expression than ICAM-1 (oneeighth and one-third, respectively), show a robust upregulation in colitic animals. These data are consistent with evidence showing that whereas in vivo constitutive level of VCAM-1 expression in a variety of organs is significantly lower than that of ICAM-1, cytokine stimulation results in a higher increase in VCAM-1 than in ICAM-1 expression (Henninger et al, 1997). Likewise, a previous study in the TNBS-induced colitis in the rat showed a marginal, not significant, increase in ICAM-1 expression along with a marked up-regulation of VCAM-1 in the colonic endothelium (Sans et al, 1999). As for MAdCAM-1, our findings are in keeping with the results of previous studies showing that IL-10-deficient mice with active colitis exhibit a profound up-regulation of MAdCAM-1 in the colon (Kawachi et al, 2000) and that human tissue sections of patients with active ulcerative colitis or Crohn's disease have increased endothelial MAdCAM-1 expression as compared with normal subjects (Briskin et al, 1997). Although DSS-induced colitis affects predominantly the distal colon (Okayasu et al, 1990), we also found increased VCAM-1 expression in ileum and cecum and up-regulation of endothelial MAdCAM-1 in stomach and cecum. Up-regulation of CAMs in these vascular beds probably results from DSS-induced mucosal lesions in these upper segments of the gut, whereas increased expression of these mol- ecules in the mesentery might be induced by cytokines released from the inflamed bowel.

We took advantage of fluorescence intravital microscopy to characterize changes in leukocyteendothelial cell interactions in colonic submucosal and lamina propria venules and to define the functional relevance of alterations in ICAM-1, VCAM-1, and MAdCAM-1 expression by means of immunoneutralization of these CAMs. The current study demonstrates that acute immunoneutralization of ICAM-1 in DSS-induced colitis does not modify leukocyte adhesion, whereas blockade of VCAM-1 or MAdCAM-1 decreases leukocyte adhesion to levels similar to those of control animals. We ruled out a nonspecific effect of injection of the immunoglobulins, because treatment with a nonbinding MAb did not modify leukocyte-endothelial cell adhesion. It has been shown that VCAM-1/ $\alpha_{4} \beta_{1}$ interactions have the potential to mediate rolling (Alon et al, 1995) and our results, showing that VCAM-1 immunoneutralization in colitic animals studied at Day 5 after induction of colitis abrogates the flux of rolling leukocytes, are in keeping with previous in vitro evidence. However, rolling interactions at Day 10 after induction of colitis seem to be VCAM-1-independent as long as blockade of this adhesion molecule did not affect rolling interactions at this time point. In vitro studies have also suggested that MAdCAM-1/L-selectin interactions (Berg et al, 1993) have the potential to mediate leukocyte rolling; however, we did not observe any effect of immunoneutralization of MAdCAM-1 on rolling interactions at any time point. Collectively, these observations suggest that VCAM-1 and MAdCAM-1 act as mediators of leukocyte adhesion in colonic venules of colitic mice, whereas ICAM-1 does not seem to be a molecular determinant of leukocyte adhesion in this experimental model of colitis.

To date, some studies have demonstrated the potential of CAMs as targets for therapeutic interventions, although information on the relative value of selective blockade of different CAMs is scarce. Podolsky et al (1993) showed a potent therapeutic effect of $\alpha_{4}$ integrin blockade in the cotton-top tamarin model of colitis, whereas an anti E-selectin MAb did not provide any amelioration in this model. In the current study, the comparison of the therapeutic value of selective immunoneutralization of ICAM-1, VCAM-1, or MAdCAM-1 clearly demonstrates that VCAM-1 blockade affords a significant amelioration of colitis, superior to that of ICAM-1 or MAdCAM-1 blockade. This observation is in keeping with the aforementioned study and with the findings by Hesterberg et al (1996) showing that immunoneutralization of the VCAM-1 counterreceptor $\alpha_{4} \beta_{7}$ significantly ameliorates colitis in the cotton-top tamarin model. It also extends previous evidence from our group (Sans et al, 1999) showing a key role for VCAM-1 in the pathogenesis of colitis in a different experimental model. It should be pointed out that the concept that blocking VCAM-1/ $\alpha_{4}$ interactions is superior to targeting other molecular determinants of leukocyte recruitment may not apply to all models of colitis (including human IBD), because 
the relative role of the different CAMs in leukocyte recruitment into the intestine may depend on the type of colonic inflammation, and might even change over time, as we demonstrate in the current study. Therefore, selective CAM blockade may be differentially effective for different forms of IBD.

The findings of the present work contrast with previous evidence showing a beneficial effect of ICAM-1 blockade in experimental models of colitis. Several studies reported that treatment with an antiICAM-1 MAb ameliorates various forms of experimental colitis, including acetic acid-induced (Wong et al, 1995) and DSS-induced (Hamamoto et al, 1999; Taniguchi et al, 1998) models. It has also been shown that sustained treatment for one week with an ICAM-1 antisense oligonucleotide significantly attenuates experimental DSS-induced colitis (Bennett et al, 1997). In a recent study, Bendjelloul and colleagues observed that ICAM-1 deficiency protects mice against DSS-induced colitis (Bendjelloul et al, 2000). The discrepancy between these observations and the results of the current study showing no effect of ICAM-1 blockade on leukocyte adhesion and inflammatory changes in DSS-induced colitis may have several reasons. Wong et al (1995) treated the rats with a single dose of an anti-ICAM-1 MAb 24 hours after exposing the colon to acetic acid, a time point when mucosal damage is nonimmunologic in nature but dependent on the reaction of the mucosa to organic acids and ischemia, a process that might potentially be affected by ICAM-1 blockade (Kurose et al, 1994). The reasons for the disagreement between our observations and other experimental studies using the DSSinduced colitis model are less straightforward. They might be related to species or mouse strain differences or to special features related to experimental conditions, including the concentration of DSS used (3\% in studies by Taniguchi et al and Bendjelloul et al) and duration of exposure to this toxic compound, namely continuous administration of DSS for 5 to 7 days versus administration of $5 \%$ DSS for only the initial 4 days and study at Day 10 . These methodological differences might lead to a different response in up-regulation of ICAM-1, which in our model was mild, but in the models of continuous DSS administration seems to be more robust (Bennett et al, 1997).

The lack of therapeutic effect of anti-MAdCAM-1 MAb in our study was surprising taking into account the potent inhibitory effect of acute administration of an anti-MAdCAM-1 MAb on leukocyte adhesion in colonic venules in animals studied at Day 10 after induction of colitis, which is similar to that of VCAM-1. Assessment of the effects of treatment with antiVCAM-1 and anti-MAdCAM- 1 in animals at Day 5 after induction of colitis revealed a possible explanation, showing a significant reduction in leukocyte rolling and adhesion in response to anti-VCAM-1 blockade, whereas MAdCAM-1 immunoneutralization had no significant effect on leukocyte-endothelial cell interactions. Taken together, these results support the notion that VCAM-1 plays a key role in both the early and late phases of the inflammatory response as a molecular determinant of leukocyte rolling and adhesion, whereas MAdCAM-1 contributes to leukocyte adhesion only at a later time point. Another possibility may be that the differential effect of VCAM-1 and MAdCAM-1 chronic blockade might be related to the ability of the anti-VCAM-1 MAb to interfere with other processes of the inflammatory response in addition to leukocyte adhesion, such as cell activation or binding to nonimmune cells that may retain the lymphocytes on the inflamed organ (Meng et al, 1995). Picarella et al (1997), in a colitic model of scid mice reconstituted with $\mathrm{CD}_{45 \mathrm{RB}^{\text {high }}} \mathrm{CD}^{+}{ }^{+} \mathrm{T}$ cells, demonstrated that treatment with MAbs specific for MAdCAM-1 and/or $\beta_{7}$ integrin ( $\beta$ chain of lymphocyte MAdCAM-1 counterreceptor $\alpha_{4} \beta_{7}$ ) blocks recruitment of lymphocytes into the inflamed colon and reduces the severity of colonic inflammation. This beneficial effect of MAdCAM-1 blockade in the reconstituted scid mice may be related to the fact that reconstitution was performed with $\mathrm{T}$ cells that express $\beta_{7}$. Therefore, a MAb directed against this molecule could block all lymphocytes. Interestingly, histological improvement was superior in animals treated with anti- $\beta_{7}$ (which interferes with VCAM-1 and MAdCAM-1-mediated adhesion) than in animals that were treated only with MAdCAM-1 MAb.

In conclusion, our work clearly demonstrates the superiority of VCAM-1 blockade over that of ICAM-1 or MAdCAM-1 in inducing remission of colonic inflammation. Therefore, VCAM-1 blockade by means of MAbs represents a potential novel approach for the treatment of inflammatory bowel conditions such as ulcerative colitis. Inhibition of VCAM-1 could have the advantage of preserving physiological leukocyte trafficking because this CAM is only up-regulated by inflammatory stimuli.

\section{Materials and Methods}

\section{Colitis Induction}

Male $C_{1}$ mice weighing 28-30 g were obtained from Iffa Credo (Lyon, France) and maintained on conventional housing conditions. Experimental colitis was induced in mice by giving $5 \%$ (w/v) DSS (mol wt $40 \mathrm{kd}$; ICN Biomedicals, Aurora, Ohio) in drinking water ad libitum for four days. DSS administration was then stopped and mice received drinking water alone for 6 days until study at Day 10 . The volume of drinking water was monitored in control and colitic mice in all treatment groups. Given the variable sensitivity of different mouse strains to DSS-induced colitis (Mahler et al, 1998), the dose of DSS to be used in our $C_{1}$ mice was empirically established to induce moderate to severe colitis while minimizing mortality. Control animals received drinking water without DSS. The type of colonic inflammatory infiltrate and presence of irreversible macroscopic colonic alterations such as shortening of colon length are indicative of a chronic type of colitis. The Guide for the Care and Use of Laboratory Animals (NIH publication 86-23, revised $1985)$ as well as the document "Regulation of proce- 
dures for animal experiments" (ref. 5/1995) from the Generalitat de Catalunya were followed.

\section{Study 1: Characterization of Inflammatory Changes}

Clinical parameters, including body weight, stool consistency (score: 0 , normal stools; 1 , soft stools; and 2, liquid stools), and rectal bleeding (score: 0, negative fecal occult blood test, HemoFEC; Boehringer Mannheim, Barcelona, Spain; 1, positive fecal occult blood test; and 2, visible rectal bleeding) were daily assessed in 20 animals (10 mice with DSS-induced colitis and 10 controls). The DAl was determined as a combination of the above parameters according to the scoring criteria detailed in Table 2 (Murthy et al, 1993). Mice were killed on Day 10 after the onset of colitis induction by an overdose of subcutaneous (sc) ketamine (Ketolar, Parke-Davis, Morris Klein, New Jersey) and xylazine (Sigma Chemical, St. Louis, Missouri). The colon was excised and opened by a longitudinal incision, rinsed with saline, weighed, and its length was measured after exclusion of the cecum. Distal colon samples (approximately $20 \mathrm{mg}$ ) were then excised, snap-frozen in liquid nitrogen, and stored at $-80^{\circ} \mathrm{C}$ for later assay of MPO activity. MPO activity was assessed according to a technique described by Bradley et al (1982); results are expressed as units per gram of tissue. To evaluate histological damage coIonic samples were fixed in 4\% formalin, embedded in paraffin, and sections (5-7 $\mu \mathrm{m})$ were stained with hematoxylin and eosin following standard procedures. Stains were assessed by a single pathologist in a blinded fashion (A Salas). Colitis was graded quantitatively according to previously defined criteria, which takes into account the percentage of mucosal injury, extension of total colon length, and lesion depth (Cooper et al, 1993).

\section{Study 2: Endothelial ICAM-1, VCAM-1, and MAdCAM-1 Expression}

ICAM-2, which is constitutively expressed on endothelial cells and is not up-regulated in response to cellular activation (de Fougerolles et al, 1991; Nortamo et al, 1991), was measured as an estimation of endothelial surface area relative to tissue weight. Forty mice (10 mice per group) were used to characterize endothelial expression of ICAM-1, ICAM-2, VCAM-1, and MAdCAM-1 in controls and animals with DSSinduced colitis at Day 10.

Monoclonal Antibodies. The MAbs used to quantify endothelial expression were $\mathrm{YN1} 1 / 1.7 .4$, a rat $\operatorname{lgG}_{2 b}$ directed against mouse ICAM-1 (Kumasaka et al, 1996); 3C4, a rat $\operatorname{lgG}_{2 a}$ against mouse ICAM-2 (Xu et al, 1996); MK1.91, a rat $\operatorname{lgG}_{1}$ against mouse VCAM-1 (Gerritsen et al, 1995); MECA-367, a rat $\operatorname{lgG}_{2 a}$ against mouse MAdCAM-1 (Mebius et al, 1998), and UPC-10, a nonbinding lgG (Bickel et al, 1994). YN1/1.7.4 and MK1.91 were scaled up and purified by protein A or G chromatography at Pharmacia Upjohn Laboratories (Kalamazoo, Michigan). 3C4 and MECA367 were purchased from PharMingen (San Diego, California).
UPC-10 was purchased from Sigma (Saint Louis, Missouri) and dialyzed to remove sodium azide. The binding MAbs directed against ICAM-1, ICAM-2, VCAM-1, and MAdCAM-1 were labeled with ${ }^{125}$, whereas the nonbinding MAb UPC-10 was labeled with ${ }^{131}$ I (Amersham Ibérica, Madrid, Spain). Radioiodination of the MAbs was performed by the iodogen method as previously described (Fraker and Speck, 1978). Labeled MAbs were stored at $4^{\circ} \mathrm{C}$ and used within 3 weeks after the labeling procedure. The specific activity of labeled MAbs was approximately $0.5 \mathrm{mCi} / \mathrm{mg}$.

Endothelial Expression of ICAM-1, ICAM-2, VCAM-1, and MAdCAM-1. Animals were anesthetized with sc ketamine (150 mg/kg body weight) and xylazine ( $7.5 \mathrm{mg} / \mathrm{kg}$ body weight) and the left carotid artery and a tail vein were cannulated with PE-10 tubing (Portex, Hythe, United Kingdom). For assessment of endothelial expression of ICAM-1, ICAM-2, VCAM-1, and MAdCAM-1, a mixture of $10 \mu \mathrm{g}^{125} \mathrm{I}-\mathrm{YN} 1 / 1.7 .4$ and 40 $\mu \mathrm{g}$ unlabeled $\mathrm{YN} 1 / 1.7 .4 ; 10 \mu \mathrm{g}^{125} \mathrm{I}-3 \mathrm{C} 4$ and $60 \mu \mathrm{g}$ unlabeled 3C4; $10 \mu \mathrm{g}^{125} \mathrm{I}-\mathrm{MK} 1.91$ and $20 \mu \mathrm{g}$ unlabeled MK1.91; and $10 \mu \mathrm{g}{ }^{125} \mathrm{I}-\mathrm{MECA}-367$ without additional unlabeled MECA-367 were administered, respectively. In all cases $3 \mu \mathrm{g}^{131} \mathrm{I}$-UPC-10 was added to the injection mixture. Doses of anti-ICAM-1, anti-ICAM-2, antiVCAM-1, and anti-MAdCAM-1 MAbs proved to be saturating in previous assays (Henninger et al, 1997; Langley et al, 1999; Panés et al, 1995; Panés et al, 1996). The mixture of binding and nonbinding MAbs was administered through the tail vein catheter. Blood samples were obtained through the carotid artery catheter 5 minutes after injection of the MAb mixture. Thereafter, the animals were heparinized $(1 \mathrm{mg} / \mathrm{kg}$ sodium heparin iv) and rapidly exsanguinated. Entire organs were then harvested and weighed. ${ }^{125} \mathrm{I}$ (binding MAb) and ${ }^{131} \mathrm{I}$ (nonbinding MAb) activities in each organ and $100 \mu \mathrm{l}$ aliquots of cell-free plasma were counted in a Cobra II gamma-counter (Packard, Canberra, Australia) with automatic correction for background activity and spillover. The injected activity in each experiment was calculated by counting a $3-\mu \mathrm{l}$ sample of the $300-\mu \mathrm{l}$ injection mixture containing the radiolabeled MAbs. The accumulated activity of each MAb in an organ was expressed as nanograms of binding MAb per gram of tissue. The formula used to calculate either ICAM-1, ICAM-2, VCAM-1, or MAdCAM-1 expression was as follows: Endothelial expression $=\left[\left(\mathrm{cpm}^{125} \mathrm{I}\right.\right.$ organ $\times \mathrm{g}^{-1} \times \mathrm{cpm}$ ${ }^{125} \mathrm{I}$ injected $\left.^{-1}\right)-\left(\mathrm{cpm}^{131} \mathrm{I}\right.$ organ $\times \mathrm{g}^{-1} \times \mathrm{cpm}^{131} \mathrm{I}$ injected $\left.^{-1}\right) \times\left(\mathrm{cpm}^{125} \mathrm{I}\right.$ in plasma $) /\left(\mathrm{cpm}^{131}\right.$ I in plasma $\left.)\right] \times$ ng injected MAb. This formula was modified from the original method (Eppihimer et al, 1996) to correct the tissue accumulation of nonbinding MAb for the relative plasma levels of both binding and nonbinding MAbs (Sans et al, 1999).

\section{Study 3: In Vivo Assessment of Leukocyte-Endothelial Cell Interactions in Colonic Venules}

Leukocyte-endothelial cell interactions in colonic submucosal and lamina propria venules were characterized using intravital microscopy in control animals and 
in mice at Days 5 and 10 after induction of colitis ( $\mathrm{n}=$ 10 animals per group).

Intravital Microscopy. Mice were anesthetized with sc ketamine $(150 \mathrm{mg} / \mathrm{kg})$ and xylazine $(7.5 \mathrm{mg} / \mathrm{kg})$ and a tail vein was cannulated. Throughout the experiments, rectal temperature was monitored using an electrothermometer and was maintained between 36.5 and $37.5^{\circ} \mathrm{C}$ with an infrared heat lamp. The abdomen was opened via a midline incision and a segment of the distal colon was chosen for microscopy examination, exteriorized, and covered with a cotton gauze soaked with bicarbonate buffer. Mice were then placed on an adjustable microscope stage, and the colon was extended over a nonautofluorescent coverslip that allowed observation of a $2-\mathrm{cm}^{2}$ segment of tissue. An inverted microscope (Diaphot 300; Nikon, Tokyo, Japan) with a CF Fluor $40 \times$ objective lens (Nikon) was used. A chargecoupled device (CCD) camera (model XC-77; Hamamatsu Photonics, Hamamatsu, Japan) with a C2400 CCD camera control unit and a C2400-68 intensifier head (Hamamatsu Photonics), mounted on the microscope, projected the image onto a monitor (Trinitron KX-14CP1; Sony, Tokyo, Japan), and the images were recorded using a videocassette recorder (SR-S368E; JVC, Tokyo, Japan) for off-line analysis. A video date-time generator (Panasonic Digital AV Mixer WJ-AVE55; Matsushita Communication Industrial, Tokyo, Japan) displayed these parameters on recorded and live images. Leukocytes were in vivo labeled by iv injection of rhodamine-6G (Molecular Probes, Leiden, The Netherlands) as previously described (Horie et al, 1997). Rhodamine-6G-associated fluorescence was visualized by epi-illumination at 510-560 nm, using a $590 \mathrm{~nm}$ emission filter. Single unbranched submucosal and lamina propria venules with internal diameters (ID) of 25-40 $\mu \mathrm{m}$ were selected for observation. Venular ID was measured on-line using a video caliper (Microcirculation Research Institute, Texas A\&M University, College Station, Texas). The flux of rolling leukocytes, leukocyte rolling velocity, number of adherent leukocytes, venular blood flow (Vbf), and venular wall shear rate $(\gamma)$ were determined off-line after playback of the videotapes. Rolling leukocytes were defined as those white blood cells that moved at a velocity less than that of free-flowing leukocytes in the same vessel. The flux of rolling leukocytes was measured as the number of rolling leukocytes that passed a fixed point within a small $(10 \mu \mathrm{m})$ viewing area of the vessel in a 1-minute period. Leukocyte rolling velocity was calculated as the mean of 10 rolling leukocyte velocities and expressed in $\mu \mathrm{m} / \mathrm{s}$. Leukocytes were considered adherent to venular endothelium when stationary for 30 seconds or longer, and expressed as the number per $100 \mu \mathrm{m}$ length of venule. Venular blood flow was estimated from the mean of the velocity of three free-flowing leukocytes (ffv), using the empirical relationship of $\mathrm{Vbf}=\mathrm{ffv} / 1.6$ (Davis, 1987). Venular wall shear rate was calculated, assuming cylindrical geometry, using the Newtonian definition $\gamma$ $=8$ (Vbf/ID) (Lipowsky et al, 1978). In each animal, three to six random venules were examined and results were calculated as the mean of each parameter in all venules examined.

Role of ICAM-1, VCAM-1, and MAdCAM-1 in Colonic Leukocyte Recruitment. Groups of colitic mice were studied at Days 5 and 10 after induction of colitis. Animals received two doses of the following MAbs: anti-ICAM-1 (YN1/1.7.4, $50 \mu \mathrm{g})$, anti-VCAM-1 (MK1.91, $30 \mu \mathrm{g}$ ), anti-MAdCAM-1 (MECA-367, $10 \mu \mathrm{g}$ ), or a nonbinding control MAb (UPC-10, $10 \mu \mathrm{g})$. Each treatment group included five mice. The first dose of MAb was injected through the tail vein (volume $0.3 \mathrm{ml}$ ) in animals immobilized in a restrainer. Three hours later they were anesthetized with sc ketamine (150 $\mathrm{mg} / \mathrm{kg})$ and xylazine $(7.5 \mathrm{mg} / \mathrm{kg}$ ) and a second dose of the corresponding MAb was injected through a tail vein catheter. After a 30-minute equilibration period, leukocyte-endothelial cell interactions were assessed as described above.

\section{Study 4: Effect of Treatment with Anti-ICAM-1, Anti-VCAM-1, and Anti-MAdCAM-1 MAbs on DSS-Induced Colitis}

To assess the relative importance of ICAM-1, VCAM-1, and MAdCAM-1 on colonic inflammatory response to DSS, the effect of chronic treatment with YN1/1.7.4, MK1.91, MECA-365, and UPC-10, an irrelevant control MAb, was determined. Initially, a pharmacokinetic study of these MAbs was performed after intraperitoneal (ip) administration of different doses (1, 2 , or $3 \mathrm{mg} / \mathrm{kg}$ ) of ${ }^{125} \mathrm{I}$-labeled MAbs to colitic mice. Based on plasma concentrations, the MAb doses selected for daily ip administration were: $3 \mathrm{mg} / \mathrm{kg}$ for anti-ICAM-1, $2 \mathrm{mg} / \mathrm{kg}$ for anti-VCAM-1, and $1 \mathrm{mg} / \mathrm{kg}$ for anti-MAdCAM-1 and UPC-10 (control group). The calculated half-life was 24-30 hours. In all cases circulating levels 5 hours after ip injection were 4-12 $\mu \mathrm{g} / \mathrm{ml}$, whereas trough concentrations at 24 hours were less than $3 \mu \mathrm{g} / \mathrm{ml}$. Four groups of colitic mice ( $\mathrm{n}$ $=5$ per group) were treated just before induction of colitis and during the following 10 days with the aforementioned MAbs. Body weight and clinical signs of colitis were recorded daily, and animals were sacrificed at Day 10 after induction of colitis. Colonic microscopic damage was evaluated in a blinded fashion using the validated index described above. MPO activity was also measured in colonic samples.

\section{Statistical Analyses}

Data were analyzed using standard statistical methods: analysis of variance with the Bonferroni (posthoc) test and Student's unpaired $t$ test, when appropriate. All values are expressed as mean \pm SEM. Statistical significance was set at $p<0.05$.

\section{Acknowledgement}

The authors thank Sebastian Videla for excellent technical assistance with the DSS model of colitis. 


\section{References}

Alon R, Kassner PD, Carr MW, Finger EB, Hemler ME, and Springer TA (1995). The integrin VLA-4 supports tethering and rolling in flow on VCAM-1. J Cell Biol 128:1243-1253.

Bendjelloul F, Maly P, Mandys V, Jirkovska M, Prokesova L, Tuckova L, and Tlaskalova-Hogenova H (2000). Intercellular adhesion molecule-1 (ICAM-1) deficiency protects mice against severe forms of experimentally induced colitis. Clin Exp Immunol 119:57-63.

Bennett CF, Kornbrust D, Henry S, Stecker K, Howard R, Cooper S, Dutson S, Hall W, and Jacoby HI (1997). An ICAM-1 antisense oligonucleotide prevents and reverses dextran sulfate sodium-induced colitis in mice. J Pharmacol Exp Ther 280:988-1000.

Berg EL, McEvoy LM, Berlin C, Bargatze RF, and Butcher EC (1993). L-selectin-mediated lymphocyte rolling on MAdCAM-1. Nature 366:695-698.

Bickel U, Kang YS, Yoshikawa T, and Pardridge WM (1994). In vivo demonstration of subcellular localization of antitransferrin receptor monoclonal antibody-colloidal gold conjugate in brain capillary endothelium. J Histochem Cytochem 42:1493-1497.

Bradley PP, Priebat DA, Christensen RD, and Rothstein G (1982). Measurement of cutaneous inflammation: Estimation of neutrophil content with an enzyme marker. J Invest Dermatol 78:206-209.

Briskin M, Winsor Hines D, Shyjan A, Cochran N, Bloom S, Wilson J, McEvoy LM, Butcher EC, Kassam N, Mackay CR, Newman W, and Ringler DJ (1997). Human mucosal addressin cell adhesion molecule- 1 is preferentially expressed in intestinal tract and associated lymphoid tissue. Am J Pathol 151:97-110.

Cooper HS, Murthy SN, Shah RS, and Sedergran DJ (1993). Clinicopathologic study of dextran sulfate sodium experimental murine colitis. Lab Invest 69:238-249.

Davis MJ (1987). Determination of volumetric flow in capillary tubes using an optical Doppler velocimeter. Microvasc Res 34:223-230.

de Fougerolles AR, Stacker SA, Schwarting R, and Springer TA (1991). Characterization of ICAM-2 and evidence for a third counter-receptor for LFA-1. J Exp Med 174:253-267.

Eppihimer MJ, Wolitzky B, Anderson DC, Labow MA, and Granger DN (1996). Heterogeneity of expression of E- and P-selectins in vivo. Circ Res 79:560-569.

Fraker PJ and Speck JC (1978). Protein and cell membrane iodination with a sparingly soluble chloramine. Biochem Bioph Res Co 80:849-856.

Gerritsen ME, Shen CP, McHugh MC, Atkinson WJ, Kiely JM, Milstone DS, Luscinskas FW, and Gimbrone-MA J (1995). Activation-dependent isolation and culture of murine pulmonary microvascular endothelium. Microcirculation 2:151-163.

Hamamoto N, Maemura K, Hirata I, Murano M, Sasaki S, and Katsu K (1999). Inhibition of dextran sulphate sodium (DSS)induced colitis in mice by intracolonically administered antibodies against adhesion molecules (endothelial leucocyte adhesion molecule-1 (ELAM-1) or intercellular adhesion molecule-1 (ICAM-1)). Clin Exp Immunol 117:462-468.

Henninger DD, Panes J, Eppihimer M, Russell J, Gerritsen M, Anderson DC, and Granger DN (1997). Cytokine-induced
VCAM-1 and ICAM-1 expression in different organs of the mouse. J Immunol 158:1825-1832.

Hesterberg PE, Winsor Hines D, Briskin MJ, Soler Ferran D, Merrill C, Mackay CR, Newman W, and Ringler DJ (1996). Rapid resolution of chronic colitis in the cotton-top tamarin with an antibody to a gut-homing integrin $\alpha_{4 \beta 7}$. Gastroenterology 111:1373-1380.

Horie Y, Wolf R, Anderson DC, and Granger DN (1997). Hepatic leukostasis and hypoxic stress in adhesion molecule-deficient mice after gut ischemia/reperfusion. J Clin Invest 99:781-788.

Kawachi S, Jennings S, Panes J, Cockrell A, Laroux FS, Gray L, Perry M, van der HH, Balish E, Granger DN, Specian RA, and Grisham MB (2000). Cytokine and endothelial cell adhesion molecule expression in interleukin-10-deficient mice. Am J Physiol Gastrointest Liver Physiol 278:G734-G743.

Keelan ET, Licence ST, Peters AM, Binns RM, and Haskard DO (1994). Characterization of E-selectin expression in vivo with use of a radiolabeled monoclonal antibody. Am J Physiol 266:H278-H290.

Koizumi M, King N, Lobb R, Benjamin C, and Podolsky DK (1992). Expression of vascular adhesion molecules in inflammatory bowel disease. Gastroenterology 103:840-847.

Kubes P (1993). Polymorphonuclear leukocyte-endothelium interactions: A role for pro-inflammatory and antiinflammatory molecules. Can J Physiol Pharmacol 71:88-97.

Kumasaka T, Quinlan WM, Doyle NA, Condon TP, Sligh J, Takei F, Beaudet A, Bennett CF, and Doerschuk CM (1996). Role of the intercellular adhesion molecule-1(ICAM-1) in endotoxin-induced pneumonia evaluated using ICAM-1 antisense oligonucleotides, anti-ICAM-1 monoclonal antibodies, and ICAM-1 mutant mice. J Clin Invest 97:2362-2369.

Kurose I, Anderson DC, Miyasaka M, Tamatani T, Paulson JC, Todd RF, Rusche JR, and Granger DN (1994). Molecular determinants of reperfusion-induced leukocyte adhesion and vascular protein leakage. Circ Res 74:336-343.

Langley RR, Russell J, Eppihimer MJ, Alexander SJ, Gerritsen M, Specian RD, and Granger DN (1999). Quantification of murine endothelial cell adhesion molecules in solid tumors. Am J Physiol 277:H1156-H1166.

Lipowsky HH, Kovalcheck S, and Zweifach BW (1978). The distribution of blood rheological parameters in the microvasculature of cat mesentery. Circ Res 43:738-749.

Mahler M, Bristol IJ, Leiter EH, Workman AE, Birkenmeier EH, Elson CO, and Sundberg JP (1998). Differential susceptibility of inbred mouse strains to dextran sulfate sodium-induced colitis. Am J Physiol 274:G544-G551.

Mebius RE, van Tuijl S, Weissman IL, and Randall TD (1998). Transfer of primitive stem/progenitor bone marrow cells from LT alpha-/- donors to wild-type hosts: Implications for the generation of architectural events in lymphoid B cell domains. J Immunol 161:3836-3843.

Meng $\mathrm{H}$, Marchese MJ, Garlick JA, Jelaska A, Korn JH, Gailit J, Clark RA, and Gruber BL (1995). Mast cells induce T-cell adhesion to human fibroblasts by regulating intercellular adhesion molecule- 1 and vascular cell adhesion molecule- 1 expression. J Invest Dermatol 105:789-796.

Murthy SN, Cooper HS, Shim H, Shah RS, Ibrahim SA, and Sedergran DJ (1993). Treatment of dextran sulfate sodiuminduced murine colitis by intracolonic cyclosporin. Dig Dis Sci 38:1722-1734. 
Nortamo P, Li R, Renkonen R, Timonen T, Prieto J, Patarroyo M, and Gahmberg CG (1991). The expression of human intercellular adhesion molecule-2 is refractory to inflammatory cytokines. Eur J Immunol 21:2629-2632.

Okayasu I, Hatakeyama S, Yamada M, Ohkusa T, Inagaki Y, and Nakaya R (1990). A novel method in the induction of reliable experimental acute and chronic ulcerative colitis in mice. Gastroenterology 98:694-702.

Oshitani N, Campbell A, Bloom S, Kitano A, Kobayashi K, and Jewell DP (1995). Adhesion molecule expression on vascular endothelium and nitroblue tetrazolium reducing activity in human colonic mucosa. Scand $\mathrm{J}$ Gastroenterol 30:915-920.

Panés J and Granger DN (1998). Leukocyte-endothelial cell interactions: Molecular mechanisms and implications in gastrointestinal disease. Gastroenterology 114:1066-1090.

Panés J, Perry MA, Anderson DC, Manning A, Leone B, Cepinskas G, Rosenbloom CL, Miyasaka M, Kvietys PR, and Granger DN (1995). Regional differences in constitutive and induced ICAM-1 expression in vivo. Am J Physiol 269: $\mathrm{H} 1955-\mathrm{H} 1964$.

Panés J, Perry MA, Anderson DC, Muzykantov VR, Carden DL, Miyasaka M, and Granger DN (1996). Portal hypertension enhances endotoxin-induced intercellular adhesion molecule 1 up-regulation in the rat. Gastroenterology 110:866-874.

Picarella D, Hurlbut P, Rottman J, Shi X, Butcher E, and Ringler DJ (1997). Monoclonal antibodies specific for beta 7 integrin and mucosal addressin cell adhesion molecule-1 (MAdCAM-1) reduce inflammation in the colon of scid mice reconstituted with $\mathrm{CD}_{45 \mathrm{RB}}{ }^{\text {high }} \mathrm{CD}^{+}{ }^{+} \mathrm{T}$ cells. J Immunol 158:2099-2106.
Podolsky DK, Lobb R, King N, Benjamin CD, Pepinsky B, Sehgal P, and deBeaumont M (1993). Attenuation of colitis in the cotton-top tamarin by anti- $\alpha 4$ integrin monoclonal antibody. J Clin Invest 92:372-380.

Sans M, Panes J, Ardite E, Elizalde JI, Arce Y, Elena M, Palacin A, Fernandez-Checa JC, Anderson DC, Lobb R, and Pique JM (1999). VCAM-1 and ICAM-1 mediate leukocyteendothelial cell adhesion in rat experimental colitis. Gastroenterology 116:874-883.

Springer TA (1990). Adhesion receptors of the immune system. Nature 346:425-434.

Taniguchi T, Tsukada H, Nakamura H, Kodama M, Fukuda K, Saito T, Miyasaka M, and Seino $Y$ (1998). Effects of the anti-ICAM-1 monoclonal antibody on dextran sodium sulphate-induced colitis in rats. J Gastroenterol Hepatol 13:945-949.

Wong PY, Yue G, Yin K, Miyasaka M, Lane CL, Manning AM, Anderson DC, and Sun FF (1995). Antibodies to intercellular adhesion molecule-1 ameliorate the inflammatory response in acetic acid-induced inflammatory bowel disease. J Pharmacol Exp Ther 274:475-480.

Xu H, Bickford JK, Luther E, Carpenito C, Takei F, and Springer TA (1996). Characterization of murine intercellular adhesion molecule-2. J Immunol 156:4909-4914. 